\title{
Metastatic melanoma - a review of current and future drugs
}

\author{
Tiago Rodrigues Velho \\ Faculty of Lisbon, University of Lisbon, Lisbon, Portugal
}

\begin{abstract}
Background: Melanoma is one of the most aggressive cancers, and it is estimated that 76,250 men and women will be diagnosed with melanoma of the skin in the USA in 2012. Over the last few decades many drugs have been developed but only in 2011 have new drugs demonstrated an impact on survival in metastatic melanoma.

Methods: A systematic search of literature was conducted, and studies providing data on the effectiveness of current and/or future drugs used in the treatment of metastatic melanoma were selected for review. This review discusses the advantages and limitations of these agents, evaluating past, current and future clinical trials designed to overcome such limitations.

Results: To date, there are four drugs approved by the Food and Drug Administration for melanoma (dacarbazine, interleukin-2, ipilimumab and vemurafenib). Despite efforts to develop new drugs, few of them have demonstrated any clinical benefits. Approved in 1975, dacarbazine remains the gold standard in chemotherapy, although ipilimumab and vemurafenib have raised many hopes in the last few years. Combining dacarbazine or other chemotherapy agents with new pharmacological agents may be a new way to achieve better clinical responses in patients with metastatic melanoma.

Discussion: Advances in the molecular knowledge of melanoma have led to major improvements in the treatment of patients with metastatic melanoma, providing new targets and insights. However, heterogeneity amongst study populations, different approaches to treatment and the different melanoma types and localisations included in the trials makes their comparison difficult. New studies focusing on drugs developed in recent decades are warranted.

Keywords: abraxane, axitinib, carboplatin, bevacizumab, bortezomib, dacarbazine, dabrafenib, etaracizumab, everolimus, imatinib, ipilimumab, lenvatinib, olimersen, malignant melanoma, new therapeutic agents, paclitaxel, review, sorafenib, sunitinib, temozolomide, temsirolimus, trametinib, tremelimumab, vemurafenib
\end{abstract}

Citation

Provenance

Dates

Copyright

Correspondence address

Email

Competing interests
Velho TR. Metastatic melanoma - a review of current and future drugs. Drugs in Context 2012: 212242. doi:10.7573/dic.212242

Invited; externally peer reviewed

Submitted: 16 August 2012; Accepted, subject to peer review: 20 August 2012; Published: 19 November 2012

(c) 2012 Velho TR. This is an open-access article distributed under the terms of the Creative Commons Attribution License (CC-BY-NC-ND 3.0) which allows unrestricted sharing, copying and distribution for personal use provided it is properly attributed. Commercial use is not permitted.

TR Velho, Faculdade de Medicina da Universidade de Lisboa, Av. Professor Egas Moniz - 1064-028 Lisboa, Portugal

tiagovelho@campus.ul.pt

The Author has declared that there are no competing interests

\section{Introduction}

Malignant melanoma is a tumour that arises from melanocytes or from cells that develop from melanocytes. In 2010, approximately 68,130 new cases of melanoma were diagnosed, of which 8700 patients (approximately 12.8\%) died of this disease in the United States [1]. In 2012, it is estimated that 76,250 men and women (44,250 men and 32,000 women) will be diagnosed with melanoma of the skin and 9180 men and women will die from it in the USA [2]. From 2005-2009 the median age of diagnosis was 61 years [2].

Melanomas may develop in a pre-existing lesion or in healthy-appearing skin. Lesions like common acquired nevus, dysplastic nevus, congenital nevus and cellular blue nevus can be precursors of melanoma. Approximately $5-10 \%$ of melanomas are hereditary and of these $20-40 \%$ are associated with a pathogenic mutation in the cyclin-dependent kinase inhibitor 2A p16 (CDKN2A/p16) [3, 4]. In fact, individuals at highest known risk for the development of melanoma are those who carry a CDKN2A/p16 mutation [5]. However, there are other genes implicated in the development of melanoma, such as cyclin-dependent kinase 4 (CDK4), retinoblastoma protein-1 (RB1), cyclin-dependent kinase inhibitor 2A p19 (CDKN2A/p19), phosphatase and tensin homologue deleted on chromosome 10 (PTEN) and rat sarcoma (RAS).

Risk factors for melanoma include: (i) ultraviolet radiation - ultraviolet A (UVA) and ultraviolet B (UVB) [6]; (ii) acute, intense and intermittent sunburns (especially on areas of the body that only occasionally receive sun exposure); (iii) changing mole, dysplastic nevi in familial melanoma, more than 50 nevi ( $2 \mathrm{~mm}$ or greater in diameter), one family member with melanoma, previous history of melanoma, sporadic dysplastic nevi, congenital nevus, immunosuppression, sun sensitivity and freckling. Individuals with an inability to tan and with skin that sunburns easily, have a greater risk of developing melanoma [7].

In particular, metastasised melanoma has a poor prognosis, with a five-year survival rate of $15.1 \%$ [2]. The prognosis is worse when the tumour has disseminated to distant sites and visceral organs, with a median survival time of only 6-9 months and a 3-year survival rate of only $10-15 \%$ [8]. In a meta-analysis of 42 Phase II trials in advanced melanoma (2100 patients treated between 1975 and 2005), the median 
overall survival (OS) time was 6.2 months, with a 1-year survival rate of $25.5 \%$. The median progression-free survival (PFS) rate was 1.7 months, with a 6-month PFS rate of $14.5 \%[9]$.

Metastatic melanoma is highly resistant to chemotherapy, radiation therapy, hormonal therapy and modern immunotherapeutic approaches. However, new drugs have recently been approved and there are data suggesting new efficient approaches to treat melanoma. In the last few decades OS has improved slightly, mainly due to earlier diagnosis. Nevertheless, no significant impact on survival has been made despite improvements in response rates achieved with new drugs or new combinations of drugs. This article reviews current data on the most used agents in the treatment of metastatic melanoma, as well as available data regarding the promising new drugs developed in the last few years.

\section{Method}

\section{Search strategy}

A systematic search of the literature published between January 1980 and September 2012 was conducted on drugs used in the treatment of metastatic melanoma, including approved and recently designed drugs (Figure 1). The search was performed in PubMed and followed a pre-established term list, using search terms 'malignant melanoma', 'advanced melanoma', 'metastatic melanoma', 'chemotherapy', 'treatment' and 'therapy'. A language restriction to English was applied. Some references cited in the selected articles were also screened or included in the current review to identify additional potentially eligible drugs or to provide a better understanding of molecular pathways. Some unpublished studies, abstracts, posters and reviews were also included in this review, although editorials, case reports, lectures and commentaries were omitted.

\section{Inclusion criteria for studies}

Abstracts of identified articles were screened and studies not meeting the following inclusion criteria were omitted: (i) development and evaluation of a drug or a combination of drugs in metastatic melanoma; (ii) the drugs were administered to individuals or groups with diagnosed metastatic melanoma; (iii) the study included data for a number of patients and tumours, tumour response and route of drug administration; (iv) studies with eligible study designs: randomised clinical trials (RCT), cohort studies, case-control studies and case series; (v) the paper was not a case study; (vi) the paper was published in English.

Figure 1. Selection process for the studies included in the systematic review.

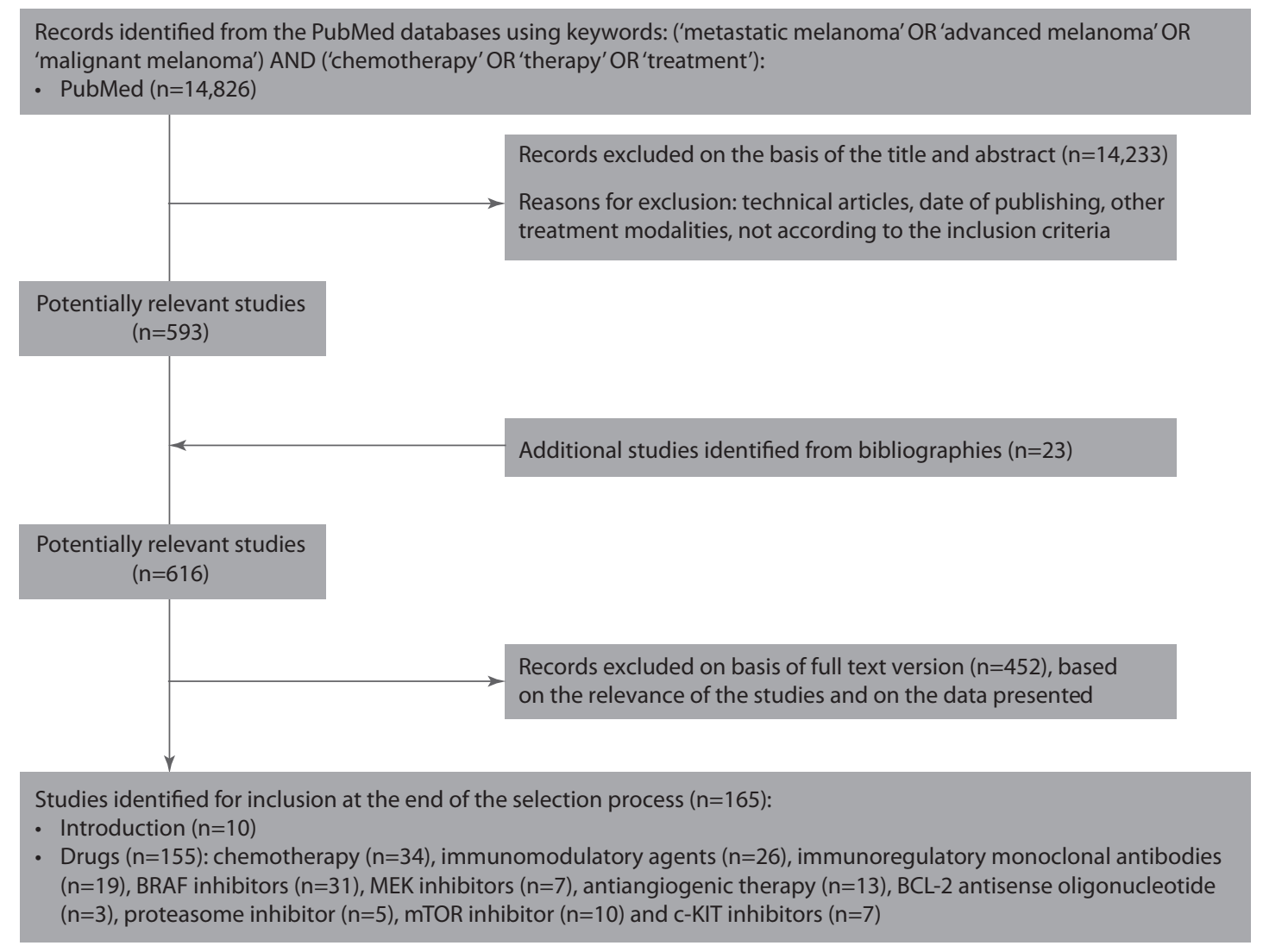

Abbreviations

BCL-2, antisense oligonucleotide; BRAF, v-Raf murine sarcoma viral oncogene homolog B1; C-KIT, v-kit Hardy-Zuckerman 4 feline sarcoma viral oncogene homolog; MEK, mitogen-activated protein kinase kinase; mTOR, mechanistic target of rapamycin doi: 10.7573/dic.212242.f001 


\section{Study selection and data collection}

The initial search identified 14,826 studies for potential review. After applying inclusion and exclusion criteria, and on the basis of the title and abstract, 14,233 studies were excluded and 593 studies were identified as potentially relevant. Twenty-three additional studies were identified from bibliographies, achieving 616 potentially relevant studies. On the basis of the full text version (based on the relevance of the studies and on the data presented), 165 studies were included in the review.

The author examined the studies identified using the search strategy, selected those for further evaluation, read the complete text and extracted the relevant data (for example, author name, year of publication, number and gender of patients, tumour response, drugs used, route of drug administration, OS time and PFS rate). If similar data were found in several studies, the most comprehensive and complete study was used.

\section{Chemotherapy}

\section{Dacarbazine}

Dacarbazine is an alkylating agent approved by the United States Food and Drug Administration (FDA) for the treatment of melanoma. Dacarbazine is one of the most effective chemotherapy agents for metastatic melanoma. Using dacarbazine as a single agent, Serrone et al. reported an approximately $20 \%$ objective response rate, with a median response duration of 5-6 months and complete response rate of 5\% [10]. Middleton et al. reported a 6.4-month median survival time in a randomised Phase III study of patients treated with dacarbazine (intent-to-treat population) [11]. In a pooled analysis of 23 randomised, controlled trials, Lui et al. showed that the objective response rate for 1390 patients receiving dacarbazine monotherapy ranged between $5.3 \%$ and $28 \%$ (average $15.3 \%)$, concluding that treatment generally results in poor outcomes [12]. In patients treated with dacarbazine monotherapy, a long-term sustained complete response occurs in $1-2 \%$ of patients and fewer than $2 \%$ of patients are alive at 6 years [13]. However, Coates et al. showed that a small group of patients, with metastases to the lungs, good performance status and normal blood lactate dehydrogenase enzyme levels, can achieve long-term disease control with a good quality of life, and some of them may even achieve complete remission with a potential to cure [14].

Although it has low activity as monotherapy, dacarbazine has remained the basis for many combination chemotherapy regimens [15], including cisplatin, nitrosoureas and tubular toxins. Bottoni et al. reported complete remission of brain metastasis in three patients with Stage 4 melanoma treated with bleomycin, vincristine, lomustine and dacarbazine (BOLD). Six of the eight patients achieved clinical benefit and median survival was 12.5 months [16]. In a multicentre Phase III randomised trial using cisplatin, vinblastine and dacarbazine (CVD), Bajetta et al. observed a response rate of $21 \%$ that was increased to $33 \%$ by the addition of interleukin-2 (IL-2) and interferon-alfa (IFN- $\alpha$ )-2b [17]. However, a CVD regimen does not have clear survival benefits compared with best supportive care alone in patients with advanced metastatic melanoma [18]. Both BOLD and CVD regimens have induced responses by metastatic lesions in the liver, bone and brain that are commonly unresponsive to dacarbazine alone, even though they have had no impact on patient survival [10]. In a Phase II randomised study, Chiarion Sileni et al. showed that the four-drug combination dacarbazine, carmustine, cisplatin and tamoxifen (DBDT regimen) achieved an overall response rate of $26 \%$ compared with an overall response rate of $5 \%$ when using dacarbazine monotherapy [19]. The median PFS and the median survival were 4 and 9 months, respectively, for the DBDT regimen, and 2 and 7 months, respectively, for dacarbazine alone. However, this combination therapy increases toxicity with limited impact on OS [19]. Combining the DBDT regimen with low-dose IL-2 is reported to increase response rate to $32.5 \%$, median PFS to 6.2 months and median OS to 11.3 months [20].

Intravenous (IV) dacarbazine can be administered at a dose of 2 to $4.5 \mathrm{mg} / \mathrm{kg}$ for 10 days, with doses repeated every 4 weeks, or $250 \mathrm{mg} / \mathrm{m}^{2}$ for 1 to 5 days, with doses repeated every 3 weeks. Common adverse effects include nausea, vomiting, leucopenia and thrombocytopenia, although other toxicities may occur.

\section{Temozolomide}

Temozolomide is an alkylating agent related to dacarbazine. It is an orally formulated prodrug of dacarbazine, with excellent oral bioavailability. Temozolomide has been shown to penetrate the brain, representing an alternative to dacarbazine against central nervous system metastases [21].

Middleton et al. reported a median survival time of 7.7 months for patients treated with temozolomide in a randomised Phase III study. The median PFS time was significantly longer in the temozolomide-treated group compared with the dacarbazine-treated group [11], although the difference between the two treatment groups was not statistically significant (HR 1.18; 95\% CI: 0.92-1.52; $p=0.20$ ). Reporting another randomised Phase III trial, Kaufmann et al. showed a higher response rate for temozolomide combined with IFN$\alpha-2 b$ than for single-agent temozolomide (24 vs 13\%). The median OS was 9.7 months for the temozolomide plus IFN$\alpha-2 b$ group and 8.4 months for the temozolomide group [22]. In a systematic review, the response rates for temozolomide in nine single-arm Phase I or II trials ranged from 0 to $29 \%$, with complete responses observed in 0 to $17 \%$ of the patients. The median OS ranged from 3.2 to 13.1 months [23]. In the last few years new associations have been made, with Clark et al. reporting a 6-month PFS of $15 \%$, a 1 -year OS of $35 \%$ and a response rate of $13 \%$ in a Phase II trial combining temozolomide with thalidomide [24].

For the characteristics described above, temozolomide may be used as monotherapy or in association with whole brain radiation therapy for patients with brain melanoma metastases, increasing survival rates in these patients [25]. Additionally, for the treatment of unresectable brain metastases in malignant melanoma, temozolomide combined with radiotherapy may prolong survival compared with temozolomide 
without radiotherapy ( 9 vs 5 months, $p=0.04$ ) [25]. Boogerd et al. reported a stabilisation of brain metastasis in $11 \%$ of 52 advanced melanoma patients with small brain metastases $(<2 \mathrm{~cm})$ treated with temozolomide monotherapy, with a median time to neurologic progression of 7 months [26].

The choice between temozolomide and dacarbazine depends essentially on the presence or absence of brain metastases. Common adverse effects include alopecia, lymphopenia, nausea, vomiting, headache, fatigue and constipation.

\section{Antimicrotubular agents, platinum analogues and nitrosoureas}

Antimicrotubular agents such as vindesine and vinblastine (vinca alkaloids) and paclitaxel (taxanes) have been reported to have modest activity in patients with metastatic melanoma, achieving $14 \%$ and $16-17 \%$ of responses in patients, respectively [27-30].

Quagliana et al. concluded from a Phase II study that vindesine does have activity in some patients with metastatic malignant melanoma, achieving complete remissions of greater than 12 months duration in $2.5 \%$ of patients and partial remission in $17.5 \%$ of patients [27]. However, $52.5 \%$ of patients had increasing disease [27]. Moreover, a Phase II trial of vinorelbine, a semi-synthetic vinca alkaloid, showed that it has poor activity in previously treated patients with disseminated melanoma [31].

Nathan et al. reported an overall response rate of $24 \%$ in a Phase II trial with paclitaxel as a 3-hour infusion on melanoma patients [32]. In addition, Rao et al. showed that the combination of paclitaxel and carboplatin appears to have clinical activity when used as a second-line therapy after temozolomide or dacarbazine, achieving an objective partial response and clinical benefit in $26 \%$ and $45 \%$ of the patients treated, respectively [33].

A potential new drug is abraxane, an albumin-bound form of paclitaxel, already approved for breast cancer. Hersh et al. reported a median survival of 12.1 and 9.6 months, respectively, in a Phase II trial of 37 previously treated and chemotherapynaïve patients with metastatic melanoma [34]. Additionally, a Phase II trial of abraxane and carboplatin, achieved a median OS of 11.1 and 10.9 months in chemotherapy-naïve and previously treated patients, respectively [35].

Carboplatin as a single agent has induced a 19\% response rate in a Phase II trial with 26 patients with metastatic malignant melanoma [36]. However, this response rate is similar to that noted for other agents, and in vitro oxaliplatin, another platinum analogue, seems to be more effective than carboplatin or cisplatin against human melanoma cell lines [37].

Nitrosoureas such as carmustine, lomustine and fotemustine induced objective responses ranging from 13 to $18 \%$ in patients with melanoma [15]. Fotemustine is probably the most active nitrosourea, with response rates between 20 and $25 \%$ [38-40]. Fotemustine appears to be a good candidate in the treatment of brain metastases because it is able to cross the blood-brain barrier $[41,42]$.

\section{Immunomodulatory agents}

\section{Interferon alfa (IFN- $\alpha$ )-2b}

IFN- $\alpha-2 b$ is approved by the FDA for adjuvant therapy of resected high-risk melanoma, with OS and recurrence-free survival rates at 5 years of $44 \%$ and $32 \%$, respectively [ 43 ]. On the other hand, no significant improvement in PFS is reported for low and intermediate-dose IFN- $\alpha[43,44]$. In a systematic review of randomised controlled trials, Lens et al. reported median OS rates from 3.2 to $6 \%$ in patients treated with IFN- $\alpha$ [45]. High-dose IFN- $\alpha$ may improve relapse-free and OS rates $[46,47]$ but it is associated with toxicities such as fever, chills, fatigue, autoimmune events and reduced quality of life. Toxicity can be reduced with the use of pegylated IFN- $\alpha$ that is suggested to have similar efficacy in metastatic disease [48].

IFN- $\alpha$ can be used alone or in regimens with IL-2 and/or chemotherapy, with more efficacy than single-agent chemotherapy. When combined with dacarbazine, it also has effects in tumour vasculature, regulating pericytes to inhibit tumour growth [49].

\section{Interleukin-2 (IL-2)}

IL-2 is a lymphokine that stimulates T-cell proliferation and function. It was approved by the FDA in 1998 for the treatment of metastatic melanoma. High dose IL-2 seems to benefit some patients with metastatic melanoma, with complete and partial responses rates of $6 \%$ and $10 \%$, respectively $[50,51]$. More effective rates are associated with greater toxicities so many trials have been conducted to identify new ways to administer IL-2. Unfortunately, IL-2 regimens involving low-doses or subcutaneous administration produce lower response rates than regimens involving high-dose and IV administration [52]. Smith et al. reported that in patients with subcutaneous or cutaneous disease only, IL-2 with melanoma vaccine gp100:209-217(210M) [gp100] was associated with higher response rates than IL-2 alone [53].

Chemotherapy in combination with IL-2 has been tested in several trials. Regimens including carmustine, cisplatin, dacarbazine, tamoxifen or vinblastine, with or without IL-2 or IL-2 associated with IFN- $\alpha$ achieved a response rate ranging from 23 to $32.5 \%$, with an OS rate of between 4.6 and 11.3 months [20,54-57]. Quan et al. recently reported that famotidine may decrease IL-2 toxicity as it enhances lymphokine-activated killer cell activity, whilst maintaining activity against melanoma [58].

\section{Adoptive T-cell therapy (ACT) and cytolytic T-lymphocyte $(C T L)$ response}

Immunotherapeutic strategies using ACT appear to mount a powerful antitumour CTL response, provoking cell lysis by activation of the apoptotic machinery [59]. ACT can use either naturally-occurring or gene-engineered $T$ cells to mediate tumour regression in patients with metastatic cancer [60-62]. Dudley et al. reported that host lympho-depletion followed by ACT and IL-2 results in objective response rates of 50 
to $70 \%$ in patients with metastatic melanoma refractory to standard therapies [63]. ACT is a promising method of treating metastatic melanoma, achieving response rates between 49 and $72 \%$, with median complete response rates from 18 to 75 months [64-66]. ACT is not possible in all patients and tumour cells often escape apoptotic pathways, enabling their survival despite CTL attack [67]. However, in testing bortezomib to sensitise melanoma cells towards adoptive CTL attack, Seeger et al. reported that bortezomib enhanced the susceptibility of melanoma cells toward redirected CTL attack and that tumour cell lysis was not due to the direct cytotoxic effects of bortezomib [68].

\section{Immunoregulatory monoclonal antibodies}

\section{Ipilimumab}

Ipilimumab is a fully human monoclonal antibody (IgG1) that has been recently approved by the FDA for the treatment of metastatic melanoma. Melanoma is one of the most immunogenic tumours and ipilimumab blocks CTL-associated antigen 4 (CTLA-4), an immune checkpoint molecule that downregulates pathways of T-cell activation, and promotes antitumour immunity $[69,70]$. In a Phase III study, Hodi et al. tested ipilimumab plus gp100, ipilimumab alone or gp100 alone in patients with metastatic melanoma, achieving a longer OS in patients receiving ipilimumab plus gp100 or ipilimumab alone (10.0 and 10.1 months, respectively, $v$ s 6.4 months for gp100 alone) [71]. Ipilimumab also has an effect on brain metastases, with $24 \%$ of the patients in cohort $\mathrm{A}$ and $10 \%$ of the patients in cohort $\mathrm{B}$ achieving disease control (assessed with modified World Health Organization [WHO] criteria) [72]. Additionally, ipilimumab can be combined with dacarbazine, improving OS when compared with dacarbazine alone (11.2 vs 9.1 months) [73]. New trials are combining ipilimumab with radiotherapy, such as the RADVAX study, a stratified Phase I/II dose escalation trial of radiotherapy followed by ipilimumab (ClinicalTrials.gov Identifier: NCT01497808; this study is currently recruiting patients). However, one must be aware of the potential severe autoimmune side-effects of ipilimumab, as it leads to immune-related adverse events, including rashes, diarrhoea, hepatitis, pancreatitis and neuropathies [74].

\section{Tremelimumab}

Tremelimumab is a fully human monoclonal antibody (IgG2) directed against the CTLA- 4 receptor. Tremelimumab can be safely administered to humans as a single IV dose up to $15 \mathrm{mg} /$ $\mathrm{kg}$ [75]. Camacho et al. reported median survival rates of 10.3 and 11 months in a Phase I/II trial, using $10 \mathrm{mg} / \mathrm{kg}$ monthly and $15 \mathrm{mg} / \mathrm{kg}$ quarterly dose regimens, respectively [76]. Evaluating tremelimumab in comparison with standard dacarbazine or temozolomide chemotherapy in previously untreated patients, Ribas et al. reported a median OS of 11.8 months in the tremelimumab group and 10.7 months in the chemotherapy group. However, tremelimumab as a single agent failed to demonstrate an improvement in OS [77]. Tremelimumab was also tested in combination with IFN- $\alpha-2 b$ achieving an OS of 21 months and a PFS of 6.4 months [78].

\section{Anti-PD-1}

Programmed death-1 (PD-1) is a negative regulator of the immune system that causes immune tolerance through apoptosis of the activated lymphocyte responsible for the evasion of melanoma cells $[79,80]$. In a Phase I study conducted by Brahmer et al., MDX-1106, a fully human immunoglobulin G4 monoclonal antibody anti-PD-1, demonstrated antitumour activity [81]. Moreover, it caused fewer immune-related adverse events than ipilimumab [81]. Topalian et al. reported that anti-PD-1 antibody produced objective responses in approximately 1 -in- 4 to 1 -in -5 patients with melanoma [82]. To verify new possibilities, a dose-escalation study combining MDX-1106 and ipilimumab in subjects with unresectable Stage 3 or Stage 4 malignant melanoma is currently recruiting patients (ClinicalTrials.gov Identifier: NCT01024231).

\section{Agonistic antibodies OX44 and anti CD137}

\section{(4-1BB)}

Antigen-specific memory T cells (Tms) are essential in the immune surveillance of residual and metastatic tumours, and the activation of Tms can be achieved by the administration of agonistic anti-CD137 monoclonal antibody [83-85]. The antibodies anti-OX44 and anti-4-1BB have an agonist action on T-cell activation and in combination these antibodies have demonstrated a promising new therapy against melanoma [86]. A Phase I study in patients with advanced cancer (including 54 patients with melanoma) demonstrated that BMS-663513, a fully human anti-CD137 agonist monoclonal antibody, had clinical activity justifying its further evaluation both as a single agent and in combination therapy [87]. A study combining anti-CD137 and ipilimumab in patients with melanoma was designed but was subsequently withdrawn prior to enrolment (ClinicalTrials.gov Identifier: NCT00803374).

\section{v-Raf murine sarcoma viral oncogene homologue B1 (BRAF) inhibitors}

\section{Non-selective BRAF inhibitors}

\section{Sorafenib}

Rapidly accelerated fibrosarcoma (RAF) is a proto-oncogene, and BRAF somatic missense mutations have been identified in 66\% of malignant melanomas analysed [88-90]. Moreover, up to $82 \%$ of benign nevi have been shown to possess activating BRAF mutations, suggesting that activation of the mitogen-activated protein kinase (MAPK) pathway is necessary for melanoma development but not sufficient for malignant transformation [91]. BRAF mutations and subsequent MAPK cascade activation have an oncogenic role in melanoma development, making BRAF inhibition a potential target for new therapies.

Sorafenib (BAY 43-9006) is a RAF tyrosine kinase inhibitor that also targets vascular endothelial growth factor receptor (VEGFR) and platelet-derived growth factor receptor 
(PDGFR). Sorafenib has been shown to inhibit MAPK pathway in vitro and in vivo [92]. As an inhibitor of the VEGFR, PDGFR and MAPK pathways, sorafenib may inhibit tumour growth by a dual mechanism, acting directly on the tumour and/or on tumour angiogenesis [93]. As a single-agent, sorafenib is well tolerated but it has not shown significant antitumour activity in advanced melanoma patients [94]. Neither has the addition of sorafenib to carboplatin and paclitaxel improved response rates and PFS [95]. However, sorafenib in combination with dacarbazine resulted in a significant improvement in PFS in patients with advanced melanoma [96]. Additionally, preliminary Phase II study results demonstrated that sorafenib in combination with temozolomide has antitumour activity, with an overall response rate of 24\% [97].

Studies are currently being conducted to confirm the efficacy of sorafenib combined with new drugs for the treatment of melanoma: i) a Phase I/II study combining sorafenib and temsirolimus has been conducted but the results have not yet been reported (ClinicalTrials.gov Identifier: NCT00349206); ii) a Phase I trial combining riluzole and sorafenib is currently recruiting participants (ClinicalTrials.gov Identifier: NCT01303341); iii) a randomised Phase II trial combining sorafenib with either temsirolimus or tipifarnib is ongoing but not recruiting participants (ClinicalTrials.gov Identifier: NCT00281957); and iv) an expanded cohort trial of bortezomib and sorafenib is currently recruiting participants (ClinicalTrials.gov Identifier: NCT01078961).

\section{RAF265}

RAF265 is a small molecular inhibitor of mutant BRAF V600E and VEGFR-2, which can be taken orally, causing dose dependent inhibition of tumour growth $[98,99]$. In the first-in-human Phase I study of RAF265, overall response rates were $16 \%$ in mutant BRAF patients and $13 \%$ in BRAF WT patients [100]. Additionally, Su et al. showed that RAF265 inhibits the growth of advanced human melanoma tumours $-41 \%$ of tumours implanted in mice responded to RAF265 treatment with more than 50\% reduction in tumour growth [101]. However, more studies are needed to confirm the efficacy and safety of RAF265 and a study is already ongoing, although not recruiting participants (ClinicalTrials.gov Identifier: NCT00304525).

\section{Selective BRAF inhibitors}

\section{Vemurafenib}

Vemurafenib is an oral, reversible and selective inhibitor of BRAF V600E [102] that is approved by the FDA for the treatment of patients with nonresectable or metastatic melanoma.

Vemurafenib was first evaluated by Flaherty et al. in a Phase I study (BRIM-1). Amongst the 32 patients with the BRAF V600E mutation, 24 (75\%) had a partial response and $2(6.25 \%)$ had a complete response, with a median PFS amongst all patients of more than 7 months [103]. A Phase II study (BRIM-2) in 132 patients with BRAF V600E mutation subsequently showed an overall response rate of 53\% $(6 \%$ of patients achieved a complete response and $47 \%$ a partial response) [104]. The Phase III study (BRIM-3) conducted by Chapman et al. compared vemurafenib to dacarbazine in 675 patients with previously untreated, metastatic melanoma with the BRAF V600E mutation [105]. At 6 months, OS was $84 \%$ in the vemurafenib arm compared with $64 \%$ in the dacarbazine arm and the median PFS was 5.3 months with vemurafenib compared with 1.6 months with dacarbazine [105]. The overall response rate was also $53 \%$ and the PFS was 6.8 months in a Phase II trial in patients with previously treated BRAF V600E mutant metastatic melanoma [106].

The most common adverse events of vemurafenib were arthralgia, rash, photosensitivity, diarrhoea, mild-to-moderate nausea, fatigue and alopecia $[105,106]$.

Vemurafenib also has activity in brain metastases in patients with BRAF V600E mutation melanoma, correlated with extra-cranial tumour response [107, 108]. Although vemurafenib is associated with a relative risk reduction of $63 \%$ in the risk of death and $74 \%$ in the risk of death or disease progression compared with dacarbazine [109], resistance to BRAF inhibition has already been observed [110]. Melanomas avoid BRAF inhibition through receptor tyrosine kinase (RTK)-mediated activation of an alternative survival pathway or activated RAS-mediated reactivation of the MAPK pathway [111]. However, combinations of $\mathrm{BRAF/mitogen-}$ activated protein kinase kinase (MEK)/extracellular signal-regulated kinase (ERK) inhibitors may potentially attenuate the problem $[110,112]$.

\section{Dabrafenib (GSK2118436)}

Dabrafenib (GSK2118436) is a selective inhibitor of mutant BRAF. In a Phase I/II study Kefford et al. reported response rates around $60 \%$ in patients with mutated BRAF melanoma [113]. Additionally, a Phase III trial concluded that dabrafenib improved PFS when compared with dacarbazine (median PFS 5.1 vs 2.7 months, respectively) [114].

Dabrafenib also has activity against brain metastases as it leads to reduction in the size of brain lesions $[115,116]$. One of the problems of selective BRAF inhibitors is the resistance acquired to treatment. Clinical trials combining BRAF, MEK and $\mathrm{PI} 3 \mathrm{~K} / \mathrm{mTOR}$ inhibitors are ongoing or planned to overcome this issue [117].

Side-effects of dabrafenib are very similar to those observed with vemurafenib, although dabrafenib is also associated with induction of keratinocytic proliferation [118].

\section{Mitogen-activated protein kinase (MEK) inhibitors}

MEK is a member of the MAPK signalling cascade that is commonly activated in melanoma [119]. These mutations render melanoma cells independent of the normal RTK-mediated pathway regulation and constitutively drive melanoma cells to oncogenic proliferation and survival [67]. Direct inhibition of MEK may therefore block cell proliferation and induce apoptosis.

Kirkwood et al. carried out a Phase II, open-label, multicentre, randomised, parallel-group trial, comparing the MEK1/2 inhibitor, selumetinib, with temozolomide, and reported no significant difference in PFS between patients 
with unresectable Stage 3/4 cutaneous melanoma unselected for BRAF/neuroblastoma RAS viral oncogene homologue (NRAS) mutations [120]. However, selumetinib combined with standard chemotherapeutic agents resulted in enhanced tumour growth inhibition in human tumour xenograft models [121]. Moreover, combination of selumetinib and Rous sarcoma oncogene (SRC) kinase inhibitor saracatinib suppressed melanoma cell growth and invasion [122].

Trametinib is a reversible and selective MEK1 and MEK2 inhibitor that has activity against melanoma. Following a Phase I dose-escalation trial of trametinib in patients with advanced melanoma, Falchook et al. reported a 33\% response rate and a median PFS of 5.7 months [123]. Trametinib also improved rates of PFS and OS when compared with chemotherapy (PFS 4.8 vs 1.5 months and OS at 6 months $81 \%$ vs $67 \%$ in the trametinib and chemotherapy groups, respectively) [124].

Many new MEK inhibitors are being developed. Von Euw et al. reported that the MEK inhibitor TAK733 has antitumour properties in cutaneous and uveal melanoma cell lines with different oncogenic mutations [125]. Inhibition of the MEK pathway seems to be promising in the treatment of melanoma, although more studies are needed.

\section{Antiangiogenic therapy}

\section{Bevacizumab}

Angiogenesis is essential to tumour growth and VEGF plays an important role in angiogenesis, regulating the proliferation and migration of endothelial cells. Bevacizumab is a humanised monoclonal antibody that inhibits vascular endothelial growth factor-A (VEGF-A). Rationally, blocking angiogenesis would be expected to enhance tumour inhibition, so recently bevacizumab and other anti-angiogenic agents have been tested in melanoma.

In a Phase II trial combining bevacizumab with dacarbazine and daily low-dose IFN- $\alpha-2 a$, Vihinen et al. reported a response rate of $23 \%$ but the regimen was associated with remarkable vascular events [126]. Moreover, Grignol et al. reported a clinical response in $24 \%$ and stabilisation of disease in $20 \%$ of patients with metastatic melanoma in a Phase II trial of bevacizumab and high-dose IFN- $\alpha-2 b$ [127].

Bevacizumab in combination with carboplatin plus paclitaxel does not appear to improve PFS in patients with untreated advanced melanoma [128]. However, von Moos et al. reported promising activity of bevacizumab in combination with temozolomide, with a median PFS and OS of 4.2 and 9.6 months, respectively [129].

Bevacizumab may be useful in the treatment of American Joint Committee on Cancer (AJCC) Stage 3 patients after therapeutic lymph node dissection [130]. New studies are needed to confirm if bevacizumab has activity when combined with new agents such as ipilimumab.

\section{Axitinib}

Axitinib is an oral tyrosine kinase inhibitor against the vascular epithelial growth factor receptors (VEGFR)-1, VEGFR-2,
VEGFR-3 and PDGFR [131, 132]. Fruehauf et al. reported that in a Phase II trial axitinib was well tolerated and had single-agent activity in metastatic melanoma, achieving a response rate of $18.8 \%$ and a 6-month PFS of 33.9\% [133]. Axitinib plus a specific peptide-based vaccine has also been shown to enhance antitumour efficacy [134]. Further investigation of this new drug is needed, and a two-arm trial of axitinib and carboplatin/paclitaxel is currently recruiting participants (ClinicalTrials.gov Identifier: NCT01174238).

\section{Lenvatinib (E7080)}

Lenvatinib (E7080) is a multi-targeted tyrosine kinase inhibitor against VEGFR, PDGFR and fibroblast growth factor receptor (FGFR) [135]. It has been shown to inhibit tumour angiogenesis [135] and so can be useful in melanoma treatment. Boss et al. reported a Phase I study of lenvatinib in patients with advanced solid tumours in which $46 \%$ of the patients had stable disease as best response [136]. A Phase I/ $\mathrm{Ib}$, multicentre, open-label, dose escalation study of lenvatinib in patients with advanced and/or metastatic melanoma has been completed but no results have been published yet (ClinicalTrials.gov Identifier: NCT00121680). Additionally, a Phase Ib/II study of lenvatinib in combination with dacarbazine compared with dacarbazine alone as first line therapy in patients with Stage 4 melanoma is ongoing but not recruiting participants (ClinicalTrials.gov Identifier: NCT01133977). These trials will help to evaluate the possible role of lenvatinib in the treatment of melanoma.

\section{Etaracizumab (MEDI-522)}

Etaracizumab (MEDI-522) is a monoclonal antibody against alphavbeta3, an important molecule for tumour-induced angiogenesis that is upregulated in metastatic melanoma [137]. In a randomised Phase II study of etaracizumab with or without dacarbazine in patients with Stage 4 metastatic melanoma, the median OS was 12.6 months for the etaracizumab group and 9.4 months for the etaracizumab plus dacarbazine group [138]. However, more studies are needed to evaluate the use of etaracizumab in melanoma.

\section{Anti-B-cell lymphoma (BCL)2 antisense oligonucleotide}

\section{Oblimersen}

Oblimersen is an anti-B-cell lymphoma (BCL) 2 antisense oligonucleotide. An antisense drug is a short sequence of RNA which hybridises with and inactivates mRNA, preventing the protein formation. As expression of BCL2 has been associated with chemoresistance by malignant melanoma cells, downregulation of BCL2 by oblimersen may offer a new approach to the treatment of melanoma [139]. In fact, compared with dacarbazine alone, oblimersen plus dacarbazine significantly improved PFS (1.6 vs 2.6 months, respectively) and overall response (7.5 vs $13.5 \%$, respectively) in patients with advanced melanoma [140]. Moreover, electroporation may optimise the response of melanoma to chemotherapy, as it has shown to 
improve the delivery of oblimersen within tumour cells in vivo in a human melanoma xenograft [141].

\section{Proteasome inhibitors}

\section{Bortezomib}

Bortezomib is a tripeptide that binds the catalytic site of the $26 S$ proteasome with high specificity and affinity, inhibiting proteasome activity [67]. Proteasome inhibitors may represent a new treatment option for melanoma as they block the nuclear factor kappa-light-chain-enhancer of the activated B cells (NF-kB) pathway, inhibiting tumour cell proliferation and sensitising them to chemotherapy [142].

Amiri et al. reported impressive results with temozolomide combined with bortezomib in an human melanoma xenograft model [143]. Moreover, in a Phase I trial of bortezomib with temozolide in patients with advanced melanoma (3 patients with primary ocular melanoma and 16 patients with primary cutaneous melanoma), Su et al. observed inhibition of proteasome activity in peripheral blood mononuclear cells [144]. However, inhibition was for a limited time period only and effects on NF- $\kappa \mathrm{B}$ activation were not consistent.

Bortezomib has also been tested in combination with paclitaxel and carboplatin in patients with metastatic melanoma, although this combination was of limited clinical benefit and was associated with significant toxicity [145]. Nevertheless, new agents may enhance bortezomib activity. Sunitinib arrests growth and sensitises melanoma cells to bortezomib, so combining sunitinib with bortezomib may provide therapeutic benefit [146]. Further studies of bortezomib are needed to evaluate the potential of this drug.

\section{Mechanistic target of rapamycin (mTOR) inhibitors}

Mechanistic target or rapamycin (mTOR) is a serine/threonine kinase downstream of protein kinase B (AKT) [147] (the major downstream effector of the phosphatidylinositol3-kinase [PI3K] pathway) that modulates protein synthesis, angiogenesis and cell cycle progression [148, 149]. As mTOR is important for tumour growth. mTOR inhibitors are plausible agents for the treatment of melanoma.

\section{Everolimus and temsirolimus}

Everolimus is an mTOR inhibitor. In a Phase II trial of everolimus in metastatic melanoma, 7 (35\%) of the 20 patients had stable disease at 16 weeks, with a PFS of 3 months [150]. Everolimus combined with bevacizumab has been shown to have moderate activity and be well tolerated in the treatment of patients with metastatic melanoma [151]. Moreover, everolimus and vatalanib (a pan-VEGFR tyrosine kinase inhibitor) in combination have additive effects, increasing anti-tumour activity in the orthotopic BL16/BL6 murine melanoma model compared to either drug monotherapy, without increasing toxicity [152]. Daily everolimus plus low-dose weekly cisplatin also has anti-tumour activity in several tumour types, including melanoma [153].
However, in a Phase II study of the mTOR inhibitor, temsirolimus, only 1 of the 33 patients with metastatic melanoma had a partial response lasting 2 months; the median time to disease progression and OS were 10 weeks and 5 months, respectively [154]. Moreover, in a Phase I study in patients with metastatic melanoma, temsirolimus combined with sorafenib resulted in significant toxicity at higher dose levels, did not have any clinical benefit in genetically unselected patients and did not inhibit P-extracellular signal-regulated kinase (PERK) [155]. Additionally, in a Phase II study of temsirolimus in combination with sorafenib in patients with untreated metastatic melanoma, only $3(4.8 \%)$ of the 63 patients achieved partial response [156].

\section{Targeting v-kit Hardy-Zuckerman 4 feline sarcoma viral oncogene homolog (c-KIT or CD117)}

c-KIT or CD117 encodes a receptor tyrosine kinase whose ligand is stem cell factor (SCF or KIT ligand). c-KIT signalling is important for melanocyte development, differentiation, proliferation, survival and migration [157, 158]. Mutations in c-KIT in melanoma have been reported [159]. Curtin et al. reported somatic activation of c-KIT in 39\% of mucosal, $36 \%$ of acral and $28 \%$ of melanomas on chronically sun-damaged skin [160]. Because of its potentially important role in melanoma oncogenesis, c-KIT may be an effective target in the treatment of melanoma.

\section{Imatinib}

Imatinib is a receptor tyrosine kinase inhibitor against Abelson proto-oncogene-breakpoint cluster region (BCR-ABL), c-KIT and PDGFR. In a Phase II trial of imatinib, 28 of the 295 patients with melanoma screened for the presence of c-KIT mutations and amplifications were treated with imatinib. The overall durable response rate was $16 \%$, with a median time to progression of 12 weeks and a median OS of 46.3 weeks [161]. In another Phase II study of imatinib in patients with metastatic melanoma and c-KIT mutations or amplification, the overall response rate was $23.3 \%$ [162].

Imatinib seems to have clinical benefit in a subset of patients who have c-KIT mutation or amplification. However, more studies are needed to confirm if imatinib is a viable treatment for such patients.

\section{Sunitinib}

Sunitinib is an oral, small molecule, multi-targeted receptor tyrosine kinase inhibitor against PDGFR, VEGFR and c-KIT. Minor et al. reported one complete remission for 15 months and two partial responses in the four evaluable patients with c-KIT mutations, and one partial response in the six patients with either c-KIT amplification or overexpression, concluding that sunitinib may have activity in patients with melanoma and c-KIT mutations [163]. Moreover, a strategy combining sunitinib and bortezomib has shown therapeutic benefits [146]. 


\section{Discussion}

Melanoma is the fifth and seventh leading cause of cancer deaths in males and females, respectively, in the USA [164].

There are 4 drugs currently approved by the FDA for the treatment of melanoma: dacarbazine, IL-2, ipilimumab and vemurafenib. Ipilimumab and vemurafenib were approved in 2011 and have raised many hopes in melanoma treatment. However, they have many limitations and their side effects have limited their use and redirected investigations towards new targets.

Dacarbazine, one of the oldest available drugs (approved in 1975), remains the gold standard in chemotherapy, achieving complete responses in $2.7-4.1 \%$ of the patients (Table 1). Combining dacarbazine or other chemotherapy agents with new pharmacological agents may represent a new way to achieve better responses in patients with metastatic melanoma. For example, high doses of IL-2 can be effective but are associated with greater toxicity. However, new data suggest that the addition of famotidine to IL-2 may decrease its toxicity as it enhances lymphokine-activated killer cell activity, whilst maintaining its activity against melanoma [58]. The CTL response is another example of the beneficial effects brought by the addition of new drugs. Although it represents a promising option for the treatment of metastatic melanoma, it is not a feasible treatment for all patients as tumour cells often escape CTL attack. However, new studies have shown that the addition of bortezomib can enhance the susceptibility of melanoma cells toward redirected CTL attack [67, 68]. Currently, ipilimumab is the most promising drug. Although it has effective response rates, its use is limited by the severe and fatal immune-related adverse reactions. However, adverse reactions can now be managed by protocol-specific guidelines, including administration of systemic corticoids and/or dose interruption/ discontinuation.

Understanding oncogenesis, growth, proliferation, survival and migration pathways of melanoma cells has provided both new targets and insights in melanoma therapy. In fact, current advances in the knowledge of melanoma oncogenesis may represent our best hope to tackle melanoma. Vemurafenib is one of the best examples in this field. It is a new possibility in patients with BRAF V600E mutations, with excellent response and survival rates. However, resistance to vemurafenib has been described. New insights in molecular knowledge and combinations of drugs like BRAF/MEK/ERK inhibitors may attenuate the problem.

Despite all the efforts made to develop new drugs, few of them have demonstrated clinical benefits. Several of them have activity in vitro or in animal models, but they achieve poor response and survival rates when they are tested in clinical trials. In the next years this problem will likely be overcome with better understanding of the suitability of patients for the different therapies.

There are some limitations to comparing clinical trials and different approaches to melanoma. The heterogeneity of the populations enrolled in the studies, the different approaches to treatment and the different types and localisations of melanoma included in the trials made it impossible to compare some studies. The absence of clinical trials comparing new treatment options with some of the older and established treatment options made evaluation even more difficult.

New studies must be conducted (Table 2) to confirm if any of the recently developed drugs alone or in combination can lead to promising clinical benefits.

Table 1. Current drugs and potential drugs in metastatic melanoma.

\begin{tabular}{|c|c|c|c|c|c|c|c|c|c|}
\hline $\begin{array}{l}\text { Study } \\
\text { reference }\end{array}$ & Drug & $\begin{array}{c}\text { Number of } \\
\text { patients } \\
\text { included }\end{array}$ & $\begin{array}{l}\text { Mean age } \\
\text { (years) }\end{array}$ & PR & CR & $\begin{array}{c}\text { OS } \\
\text { (median } \\
\text { months) }\end{array}$ & $\begin{array}{c}\mathrm{HR} \\
(95 \% \mathrm{Cl})\end{array}$ & $\begin{array}{c}\text { PFS } \\
\text { (median } \\
\text { months) }\end{array}$ & $\begin{array}{c}\mathrm{HR} \\
(95 \% \mathrm{Cl})\end{array}$ \\
\hline Middleton et al. [11] & Dacarbazine & $n=149$ & 58.8 & $9.4 \%$ & $2.7 \%$ & 6.4 & $\begin{array}{c}1.18 \\
(0.92-1.52)\end{array}$ & 1.5 & $\begin{array}{c}1.37 \\
(1.07-1.75)\end{array}$ \\
\hline Lui et al. [12] & Dacarbazine & $n=1390$ & 52.5 & $11.2 \%$ & $4.1 \%$ & - & $\begin{array}{c}1.31 \\
(1.06-1.61)\end{array}$ & - & - \\
\hline McDermott et al. & Dacarbazine & $n=50$ & 60 & $12 \%$ & $0 \%$ & 12.83 & $(10.12-18)$ & 2.93 & $(1.53-4.48)$ \\
\hline [96] & Dacarbazine + sorafenib & $\mathrm{n}=51$ & 55 & $24 \%$ & $0 \%$ & 11.4 & $(8.75-17.58)$ & 5.73 & $(4-7)$ \\
\hline Robert et al. [73] & $\begin{array}{l}\text { Dacarbazine + } \\
\text { ipilimumab }\end{array}$ & $n=250$ & 57.5 & $13.6 \%$ & $1.6 \%$ & 11.2 & $(9.4-13.6)$ & - & - \\
\hline Bedikian et al. [140] & $\begin{array}{l}\text { Dacarbazine + } \\
\text { oblimersen }\end{array}$ & $n=386$ & 59 & $10.6 \%$ & $2.8 \%$ & 9 & $\begin{array}{c}0.87 \\
(0.75-10.01)\end{array}$ & 2.6 & - \\
\hline Hersey et al. [138] & $\begin{array}{l}\text { Dacarbazine + } \\
\text { etaracizumab }\end{array}$ & $\mathrm{n}=55$ & 59.9 & $0 \%$ & $12.7 \%$ & 9.4 & $(7.6-13.1)$ & 2.6 & $(1.6-3.4)$ \\
\hline $\begin{array}{l}\text { Vihinen et al. } \\
\text { (abstract) [126] }\end{array}$ & $\begin{array}{l}\text { Dacarbazine }+ \text { IFN- } \alpha+ \\
\text { bevacizumab }\end{array}$ & $n=26$ & - & $15.4 \%$ & $7.7 \%$ & 11.5 & - & 2.3 & - \\
\hline Bottoni et al. [16] & $\mathrm{BOLD}+\mathrm{G}-\mathrm{CSF}$ & $\mathrm{n}=8$ & 57 & $0 \%$ & $37.5 \%$ & 12.5 & - & 8.5 & - \\
\hline Seigler et al. [165] & BOLD & $\mathrm{n}=91$ & - & $31 \%$ & $9 \%$ & 7.75 & - & - & - \\
\hline
\end{tabular}

\section{Abbreviations}

BCDT, carmustine, cisplatin, dacarbazine, tamoxifen and interleukin-2; BOLD, bleomycin, vincristine, lomustine and dacarbazine; CR, complete response; CVD, cisplatin, vinblastine and dacarbazine; G-CSF, granulocyte-colony stimulating factor; HR, hazard ratio; IFN- $\alpha$, interferon-alfa; IL-2, interleukin-2; 
Table 1. Current drugs and potential drugs in metastatic melanoma. (continued)

\begin{tabular}{|c|c|c|c|c|c|c|c|c|c|}
\hline $\begin{array}{l}\text { Study } \\
\text { reference }\end{array}$ & Drug & $\begin{array}{c}\text { Number of } \\
\text { patients } \\
\text { included }\end{array}$ & $\begin{array}{l}\text { Mean age } \\
\text { (years) }\end{array}$ & PR & CR & $\begin{array}{c}\text { OS } \\
\text { (median } \\
\text { months) }\end{array}$ & $\begin{array}{c}\mathrm{HR} \\
(95 \% \mathrm{Cl})\end{array}$ & $\begin{array}{c}\text { PFS } \\
\text { (median } \\
\text { months) }\end{array}$ & $\begin{array}{c}\mathrm{HR} \\
(95 \% \mathrm{Cl})\end{array}$ \\
\hline Bajetta et al. [17] & CVD & $\mathrm{n}=72$ & 51.5 & $21 \%$ & - & 12 & - & 8 & - \\
\hline Su et al. [20] & BCDT & $n=40$ & 54 & $27.5 \%$ & $5 \%$ & 11.3 & $\begin{array}{l}\text { (7.0-15.6 } \\
\text { month) }\end{array}$ & 6.2 & $(2.9-9.6)$ \\
\hline \multirow[t]{2}{*}{ Kaufmann et al. [22] } & Temozolomide & $n=134$ & 56 & $11.2 \%$ & $2.2 \%$ & 8.4 & $(7.07-9.72)$ & 2.4 & $(1.48-3.28)$ \\
\hline & Temozolomide + IFN- $\alpha$ & $\mathrm{n}=137$ & 54.5 & $16.1 \%$ & $8 \%$ & 9.7 & (8.26-11.18) & 3.3 & $(2.73-3.82)$ \\
\hline Clark et al. [24] & $\begin{array}{l}\text { Temozolomide }+ \\
\text { Thalidomide }\end{array}$ & $n=62$ & 62 & $13 \%$ & - & 8 & $(6-12)$ & 2 & $(2-4)$ \\
\hline $\begin{array}{l}\text { von Moos et al. } \\
\text { (abstract) [129] }\end{array}$ & $\begin{array}{l}\text { Temozolomide }+ \\
\text { bevacizumab }\end{array}$ & $n=62$ & 59 & $14.5 \%$ & $1.6 \%$ & 9.6 & - & 4.2 & - \\
\hline \multirow[t]{3}{*}{ Hodi et al. [71] } & Ipilimumab & $n=137$ & 56.8 & $9.5 \%$ & $1.5 \%$ & 10.1 & $(8.0-13.8)$ & 2.86 & $(2.76-3.02)$ \\
\hline & Ipilimumab + gp100 & $n=403$ & 55.6 & $5.5 \%$ & $0.2 \%$ & 10 & $(8.5-11.5)$ & 2.76 & $(2.73-2.79)$ \\
\hline & gp100 & $n=136$ & 57.4 & $1.5 \%$ & $0 \%$ & 6.4 & $(5.5-8.7)$ & 2.76 & $(2.73-2.83)$ \\
\hline $\begin{array}{l}\text { Quagliana et al. } \\
\text { (abstract) [27] }\end{array}$ & Vindesine & $n=42$ & - & $17.5 \%$ & $2.5 \%$ & - & - & - & - \\
\hline Whitehead et al. [31] & Vinorelbine & $n=21$ & 58 & $0 \%$ & $0 \%$ & 6 & $(3.7-8.3)$ & 2 & $(1.5-3.3)$ \\
\hline Hersh et al. [34] & Abraxane & $\mathrm{n}=37$ & 61.2 & $21.6 \%$ & $0 \%$ & 9.6 & $(6.7-23.7)$ & 4.5 & $(3.4--6.7)$ \\
\hline $\begin{array}{l}\text { Kottschade et al. } \\
\text { [35] }\end{array}$ & Abraxane + carboplatin & $n=39$ & 59 & $23.04 \%$ & $2.56 \%$ & 11.1 & - & 4.3 & - \\
\hline $\begin{array}{l}\text { Fruehauf J (abstract) } \\
\text { [133] }\end{array}$ & Axitinib & $n=32$ & - & $15.6 \%$ & $3.1 \%$ & 6.6 & - & - & - \\
\hline Hersey et al. [138] & Etaracizumab & $\mathrm{n}=57$ & 56.7 & $0 \%$ & $0 \%$ & 12.6 & $(6.8-14.2)$ & 1.8 & $(1.3-2.8)$ \\
\hline Croghan et al. [145] & $\begin{array}{l}\text { Paclitaxel + carboplatin+ } \\
\text { Bortezomib }\end{array}$ & $n=17$ & 59 & $11.8 \%$ & $0 \%$ & 7 & - & 3.2 & - \\
\hline $\begin{array}{l}\text { Hainsworth et al. } \\
\text { [151] }\end{array}$ & $\begin{array}{l}\text { Bevacizumab }+ \\
\text { everolimus }\end{array}$ & $\mathrm{n}=57$ & 70 & $10.5 \%$ & $1.8 \%$ & 8.6 & - & 4 & $(2.8-5.3)$ \\
\hline $\begin{array}{l}\text { Margolin et al. } \\
\text { (abstract) [156] }\end{array}$ & Temsirolimus + sorafenib & $n=63$ & - & $4.8 \%$ & $0 \%$ & 7 & - & 2.1 & - \\
\hline Carvajal et al. [161] & Imatinib & $n=28$ & 71 & $7.1 \%$ & $7.1 \%$ & 10.7 & $\begin{array}{l}\text { (6.5-not } \\
\text { achieved) }\end{array}$ & - & - \\
\hline Guo et al. [162] & Imatinib & $\mathrm{n}=43$ & 57 & $23.3 \%$ & $0 \%$ & 14 & $(10.8-17.2)$ & 3.5 & $(1.3-5.7)$ \\
\hline
\end{tabular}

\section{Abbreviations}

$B C D T$, carmustine, cisplatin, dacarbazine, tamoxifen and interleukin-2; BOLD, bleomycin, vincristine, lomustine and dacarbazine; CR, complete response; CVD, cisplatin, vinblastine and dacarbazine; G-CSF, granulocyte-colony stimulating factor; HR, hazard ratio; IFN- $\alpha$, interferon-alfa; IL-2, interleukin-2; OS, overall survival; PFS, progression-free survival; PR, partial response doi: 10.7573/dic.212242.t001 
Table 2. Future trials in melanoma research.

\begin{tabular}{|c|c|c|c|c|c|c|c|}
\hline Identifier & Clinical trial description & Condition & Intervention & $\begin{array}{l}\text { Trial } \\
\text { phase }\end{array}$ & Status & Start date & $\begin{array}{l}\text { Estimated } \\
\text { completion date }\end{array}$ \\
\hline NCT01497808 & $\begin{array}{l}\text { A Stratified Phase I/ II } \\
\text { Dose Escalation Trial } \\
\text { of Stereotactic Body } \\
\text { Radiotherapy Followed by } \\
\text { Ipilimumab in Metastatic } \\
\text { Melanoma }\end{array}$ & $\begin{array}{l}\text { Metastatic } \\
\text { melanoma }\end{array}$ & $\begin{array}{l}\text { Drug: ipilimumab } \\
\text { Radiation: stereotactic body } \\
\text { Radiation therapy }\end{array}$ & III & $\begin{array}{l}\text { Currently } \\
\text { recruiting } \\
\text { patients }\end{array}$ & $\begin{array}{l}\text { December } \\
2011\end{array}$ & $\begin{array}{l}\text { June } 2014 \\
\text { (Primary outcome } \\
\text { measure) }\end{array}$ \\
\hline NCT00803374 & $\begin{array}{l}\text { Combination of Anti-CD137 } \\
\text { \& Ipilimumab in Patients } \\
\text { With Melanoma }\end{array}$ & Melanoma & $\begin{array}{l}\text { Drug: antiCD137 } \\
\text { Drug: ipilimumab }\end{array}$ & 1 & $\begin{array}{l}\text { Withdrawn } \\
\text { prior to } \\
\text { enrolment }\end{array}$ & $\begin{array}{l}\text { November } \\
2010\end{array}$ & $\begin{array}{l}\text { Finished July } \\
2012\end{array}$ \\
\hline NCT01303341 & $\begin{array}{l}\text { Riluzole and Sorafenib } \\
\text { Tosylate in Treating Patients } \\
\text { With Advanced Solid Tumors } \\
\text { or Melanoma }\end{array}$ & $\begin{array}{l}\text { Cutaneous } \\
\text { melanoma }\end{array}$ & $\begin{array}{l}\text { Drug: riluzole } \\
\text { Drug: sorafenib tosylate } \\
\text { Other: laboratory biomarker } \\
\text { analysis } \\
\text { Other: pharmacological study }\end{array}$ & I & $\begin{array}{l}\text { Currently } \\
\text { recruiting } \\
\text { patients }\end{array}$ & February 2011 & $\begin{array}{l}\text { July } 2011 \\
\text { (Primary outcome } \\
\text { measure) }\end{array}$ \\
\hline NCT00281957 & $\begin{array}{l}\text { Sorafenib With Either } \\
\text { Temsirolimus or Tipifarnib } \\
\text { in Stage IV Melanoma That } \\
\text { Cannot Be Removed by } \\
\text { Surgery }\end{array}$ & Melanoma & $\begin{array}{l}\text { Drug: sorafenib tosylate } \\
\text { Drug: temsirolimus } \\
\text { Drug: tipifarnib }\end{array}$ & Phase II & $\begin{array}{l}\text { Ongoing, } \\
\text { but not } \\
\text { recruiting } \\
\text { participants }\end{array}$ & August 2007 & $\begin{array}{l}\text { December } 2012 \\
\text { (Primary outcome } \\
\text { measure) }\end{array}$ \\
\hline NCT01174238 & $\begin{array}{l}\text { A Two Arm Trial of Axitinib } \\
\text { and Carboplatin/Paclitaxel in } \\
\text { Melanoma (CC\# 10852) }\end{array}$ & Melanoma & $\begin{array}{l}\text { Drug: axitinib } \\
\text { Drug: carboplatin } \\
\text { Drug: paclitaxel }\end{array}$ & ॥ & $\begin{array}{l}\text { Currently } \\
\text { recruiting } \\
\text { patients }\end{array}$ & July 2010 & $\begin{array}{l}\text { July } 2015 \\
\text { (Primary outcome } \\
\text { measure) }\end{array}$ \\
\hline NCT00121680 & $\begin{array}{l}\text { A Phase I/lb, Multicenter, } \\
\text { Open-Label, Dose Escalation } \\
\text { Study of E7080 in Patients } \\
\text { With Solid Tumors and } \\
\text { in Combination With } \\
\text { Temozolomide in Patients } \\
\text { With Advanced and/or } \\
\text { Metastatic Melanoma }\end{array}$ & $\begin{array}{l}\text { Metastatic } \\
\text { melanoma }\end{array}$ & Drug: E7080 & 1 & Completed & July 2005 & $\begin{array}{l}\text { November } 2011 \\
\text { (Primary outcome } \\
\text { measure) }\end{array}$ \\
\hline NCT01133977 & $\begin{array}{l}\text { E7080 in Combination } \\
\text { With Dacarbazine Versus } \\
\text { Dacarbazine Alone as First } \\
\text { Line Therapy in Patients With } \\
\text { Stage IV Melanoma }\end{array}$ & $\begin{array}{l}\text { Stage } 4 \\
\text { melanoma }\end{array}$ & $\begin{array}{l}\text { Drug: dacarbazine } \\
\text { Drug: E7080 }\end{array}$ & $\begin{array}{l}\text { I } \\
\| 1\end{array}$ & $\begin{array}{l}\text { Ongoing, } \\
\text { but not } \\
\text { recruiting } \\
\text { participants }\end{array}$ & March 2010 & $\begin{array}{l}\text { June } 2013 \\
\text { (Primary outcome } \\
\text { measure) }\end{array}$ \\
\hline
\end{tabular}

doi: $10.7573 /$ dic.212242.t002 


\section{Funding}

The Author received an honorarium from the Publisher.

\section{References}

1. Jemal A, Siegel R, Xu J, Ward E. Cancer Statistics, 2010. CA Cancer J Clin 2010;60(5):277-300.

2. National Cancer Institute. Surveillance Epidemiology and End Results 2012. Available from: http://seer.cancer.gov/statfacts/html/melan.html\#ref11 [Last accessed: 7 August 2012].

3. Florell SR, Boucher KM, Garibotti G et al. Populationbased analysis of prognostic factors and survival in familiar melanoma. J Clin Oncol 2005;23(28):7168-77.

4. Goldstein AM, Chan M, Harland M et al. Melanoma Genetics Consortium (GenoMEL): Features associated with germline CDKN2A mutations: a GenoMEL study of melanoma-prone families from three continents. J Med Genet 2007;44(2):99-106.

5. Aspinwall L, Leaf S, Dola ER, Kohlmann W, Leachman SA. CDKN2A/p16 genetic test reporting improves early detection intentions and practices in high-risk melanoma families. Cancer Epidemiol Biomarkers Prev 2008;17(6):1510-9.

6. Ivry GB, Ogle CA, Shim EK: Role of sun exposure in melanoma. Dermatol Surg 2006;32(4):481-92.

7. Tsao H, Atkins MB, Sober AJ. Management of cutaneous melanoma. N Engl J Med 2004;351(10):998-1012.

8. Balch CM, Gershenwald JE, Soong SJ et al. Final version of 2009 AJCC melanoma staging and classification. J Clin Oncol 2009;27(36):6199-206.

9. Korn EL, Liu PY, Lee SJ et al. Meta-analysis of phase II cooperative group trials in metastatic stage IV melanoma to determine progression-free and overall survival benchmarks for future phase II trials. J Clin Oncol 2008;26(4):527-34.

10. Serrone L, Zeuli M, Sega FM, Cognetti F. Dacarbazinebased chemotherapy for metastatic melanoma: thirty-year experience overview. J Exp Clin Cancer Res 2000;19(1):21-34.

11. Middleton MR, Grob JJ, Aaronson $\mathrm{N}$ et al. Randomized phase III study of temozolomide versus dacarbazine in the treatment of patients with advanced metastatic malignant melanoma. J Clin Oncol 2000;18(1):158-66.

12. Lui P, Cashin R, Machado M, Hemels M, Corey-Lisle PK, Einarson TR. Treatments for metastatic melanoma: synthesis of evidence from randomized trials. Cancer Treat Rev 2007;33(8):665-80.

13. Hill GJ $2^{\text {nd }}$, Krementz ET, Hill HZ. Dimethyl triazeno imidazole carboxamide and combination therapy for melanoma. IV. Late results after complete response to chemotherapy (Central Oncology Group protocols 7130, 7131, and 7131A). Cancer 1984;53(6):1299-305.

14. Coates AS, Segelov E. Long term response to chemotherapy in patients with visceral metastatic melanoma. Ann Oncol 1994;5(3):249-51.
15. Gasent Blesa JM, Grande Pulido E, Alberola Candel V, Provencio Pulla M. Melanoma from darkness to promise. Am J Clin Oncol 2011;34(2):179-87.

16. Bottoni U, Bonaccorsi P, Devirgiliis V et al. Complete remission of brain metastases in three patients with stage IV melanoma treated with BOLD and G-CSF. Jpn J Clin Oncol 2005;35(9):507-13.

17. Bajetta E, Del Vecchio M, Nova P et al. Multicenter phase III randomized trial of polychemotherapy (CVD regimen) versus the same chemotherapy (CT) plus subcutaneous interleukin-2 and interferon-alpha2b in metastatic melanoma. Ann Oncol 2006;17(4):571-7.

18. Hofmann MA, Hauschild A, Mohr P et al. Prospective evaluation of supportive care with or without CVD chemotherapy as a second-line treatment in advanced melanoma by patient's choice: a multicentre Dermatologic Cooperative Oncology Group trial. Melanoma Res 2011;21(6):516-23.

19. Chiarion Sileni V, Nortilli R, Aversa SM et al. Phase II randomized study of dacarbazine, carmustine, cisplatin and tamoxifen versus dacarbazine alone in advanced melanoma patients. Melanoma Res 2001;11(2):189-96.

20. Su PJ, Chen JS, Liaw CC et al. Biochemotherapy with carmustine, cisplatin, dacarbazine, tamoxifen and low dose interleukin-2 for patients with metastatic malignant melanoma. Chang Gung Med J 2011;34(5):478-86.

21. Tatar Z, Thivat E, Planchat E et al. Temozolomide and unusual indications: Review of literature. Cancer Treat Rev 2012 Jul 18. [Epub ahead of print].

22. Kaufmann R, Spieth K, Leiter U et al. Temozolomide in combination with interferon-alfa versus temozolomide alone in patients with advanced metastatic melanoma: a randomized, phase III, multicenter study from the Dermatologic Cooperative Oncology Group. J Clin Oncol 2005;23(35):9001-7.

23. Quirt I, Verma S, Petrella T, Bak K, Charette M. Temozolomide for the treatment of metastatic melanoma: a systematic review. Oncologist 2007;12(9):1114-23.

24. Clark JI, Moon J, Hutchins LF et al. Phase 2 trial of combination thalidomide plus temozolomide in patients with metastatic malignant melanoma: Southwest Oncology Group S0508. Cancer 2010;116(2):424-31.

25. Hofmann M, Kiecker F, Wurm R et al. Temozolomide with or without radiotherapy in melanoma with unresectable brain metastases. J Neurooncol 2006;76(1): 59-64.

26. Boogerd W, de Gast GC, Dalesio O. Temozolomide in advanced malignant melanoma with small brain metastases: can we withhold cranial irradiation? Cancer 2007;109(2):306-12.

27. Quagliana JM, Stephens RL, Baker LH, Costanzi JJ. Vindesine in patients with metastatic malignant melanoma: a southwest Oncology Group study. J Clin Oncol 1984;2(4):316-9.

28. Wiernik PH and Einzig: Taxol in malignant melanoma. J Natl Cancer Inst Monogr 1993;(15):185-7. 
29. Bedikian AY, Weiss GR, Legha SS et al. Phase II trial of docetaxel in patients with advanced cutaneous malignant melanoma previously treated with chemotherapy. J Clin Oncol 1995;13(12):2895-9.

30. Einzig AI, Hochster $\mathrm{H}$, Wiernik $\mathrm{PH}$ et al. A phase II study of taxol in patients with malignant melanoma. Invest New Drugs 1991;9(1):59-64.

31. Whitehead RP, Moon J, McCachren SS et al. A Phase II trial of vinorelbine tartrate in patients with disseminated malignant melanoma and one prior systemic therapy: a Southwest Oncology Group study. Cancer 2004;100(8):1699-704.

32. Nathan FE, Berd D, Sato T, Mastrangelo MJ. Paclitaxel and tamoxifen: An active regimen for patients with metastatic melanoma. Cancer 2000;88(1):79-87.

33. Rao RD, Holtan SG, Ingle JN et al. Combination of paclitaxel and carboplatin as second-line therapy for patients with metastatic melanoma. Cancer 2006;106(2):375-82.

34. Hersh EM, O'Day SJ, Ribas A et al. A Phase 2 clinical trial of nab-paclitaxel in previously treated and chemotherapy-naïve patients with metastatic melanoma. Cancer 2010;116(1):155-63.

35. Kottschade LA, Suman VJ, Amatruda T 3rd et al. A phase II trial of nab-paclitaxel (ABI-007) and carboplatin in patients with unresectable stage IV melanoma: a North Central Cancer Treatment Group Study, N057E(1). Cancer 2011;117(8):1704-10.

36. Evans LM, Casper ES, Rosenbluth R. Phase II trial of carboplatin in advanced malignant melanoma. Cancer Treat Rep 1987;71(2):171-2.

37. Mohammed MQ, Retsas S. Oxaliplatin is active in vitro against human melanoma cell lines: comparison with cisplatin and carboplatin. Anticancer Drugs 2000;11(10):859-63.

38. Kleeberg UR, Engel E, Israels $P$ et al. Palliative therapy of melanoma patients with fotemustine. Inverse relationship between tumour load and treatment effectiveness. A multicentre phase II trial of the EORTCMelanoma Cooperative Group (MCG). Melanoma Res 1995;5(3):195-200.

39. Calabresi F, Aapro M, Becquart D et al. Multicenter phase II trial of the single agent fotemustine in patients with advanced malignant melanoma. Ann Oncol 1991;2(5):377-8.

40. Jacquillat C, Khavat D, Banzet P et al. Final report of the French multicenter phase II study of the nitrosourea fotemustine in 153 evaluable patients with disseminatd malignant melanoma including patients with cerebral metastases. Cancer 1990;66(9):1873-8.

41. Khavat D, Giroux B, Berille J et al. Fotemustine in the treatment of brain primary tumors and metastases. Cancer Invest 1994;12(4):414-20.

42. Quéreux G, Dréno B. Fotemustine for the treatment of melanoma. Expert Opin Pharmacother 2011;12(18):2891-904.
43. Hancock BW, Wheatley K, Harris $S$ et al. Adjuvant interferon in high-risk melanoma: the AIM HIGH Study-United Kingdom Coordinating Committee on Cancer Research randomized study of adjuvant low-dose extended-duration interferon Alfa-2a in high-risk resected malignant melanoma. J Clin Oncol 2004;22(1):3-61.

44. Eggermont AM, Sociu S, MacKie R et al. EORTC Melanoma Group: Post-surgery adjuvant therapy with intermediate doses of interferon alfa $2 b$ versus observation on patients with stage IIb/III melanoma (EORTC 18952): randomized controlled trial. Lancet 2005;366(9492):1189-96.

45. Lens MB, Dawes M. Interferon alfa therapy for malignant melanoma: a systematic review of randomized controlled trials. J Clin Oncol 2002;20(7):1818-25.

46. Kirkwood JM, Strawderman MH, Ernstoff MS, Smith TJ, Borden EC, Blum RH. Interferon alfa-2b adjuvant therapy of high-risk resected cutaneous melanoma: the Eastern Cooperative Oncology Group trial EST 1684. J Clin Oncol 1996;14(1):7-17.

47. Kirkwood JM, Ibrahim JG, Sondak VK et al. High- and low-dose interferon alfa- $2 \mathrm{~b}$ in high-risk melanoma: first analysis of intergroup trial E1690/S9111/C9190. J Clin Oncol 2000;18(12):2444-58.

48. Dummer R, Garbe C, Thompson JA et al. Randomized dose-escalation study evaluating peginterferon alfa-2a in patients with metastatic malignant melanoma. J Clin Oncol 2006;24(7):1188-94.

49. Liu P, Zhang C, Chen J et al. Combinational therapy of interferon- $\alpha$ and chemotherapy normalizes tumor vasculature by relugating pericytes including the novel marker RGS5 in melanoma. J Immunother 2011;34(3): 320-6.

50. Atkins MB, Lotze MT, Dutcher JP et al. High-dose recombinant interleukin 2 therapy for patients with metastatic melanoma: analysis of 270 patients treated between 1985 and 1993. J Clin Oncol 1999;17(7):2105-16.

51. Atkins MB, Kunkel L, Sznol M, Rosenberg SA. Highdose recombinant interleukin-2 therapy in patients with metastatic melanoma: long-term survival update. Cancer J Sci Am 2000;6 Suppl 1:S11-4.

52. Keiholz U, Conradt C, Legha SS et al. Results of interleukin-2-based treatment in advanced melanoma: a case record-based analysis of 631 patients. J Clin Oncol 1998;16(9):2921-9.

53. Smith FO, Downey SG, Klapper JA et al. Treatment of metastatic melanoma using interleukin-2 alone or in conjunction with vaccines. Clin Cancer Res 2008;14(17):5610-8.

54. Johnston SR, Constenla DO, Moore J et al. Randomized phase II trial of BCDT [carmustine (BCNU), cisplatin, dacarbazine (DTIC) and tamoxifen] with or without interferon alpha (IFN-alpha) and interleukin (IL-2) in patients with metastatic melanoma. Br J Cancer 1998;77(8):1280-6. 
55. Kirchner HH, Atzpodien J, Poliwoda H. Chemo-/ immunotherapy in advanced malignant melanoma: carboplatin and DTIC or cisplatin, dtic, bcnu and tamoxifen followed by immunotherapy with interleukin 2 and interferon alpha-2a. Med Klin (Munich) 1996;91 Suppl 3:44-9.

56. González Astorga B, Jiménez Rubiano B, Delgado Pérez JR et al. Biochemotherapy in the treatment of metastatic melanoma in selected patients. Clin Transl Oncol 2009;11(6):382-6.

57. Atzpodien J, Lopez-Hänninen $\mathrm{E}$, Kirchner $\mathrm{H}$ et al. Chemoimmunotherapy of advanced malignant melanoma sequential administration of subcutaneous interleukin-2 and interferon-alpha after intravenous dacarbazine and carboplatin or intravenous dacarbazine, cisplatin, carmustine and tamoxifen. Eur J Cancer 1995;31A(6):876-81.

58. Quan WD Jr, Quan FM, Perez M, Johnson E. Outpatient Intravenous Interleukin-2 with Famotidine Has Activity in Metastatic Melanoma. Cancer Biother Radiopharm 2012 [Epub ahead of print].

59. Bleackley RC. A molecular view of cytotoxic $T$ lymphocyte induced killing. Biochem Cell Biol 2005;83(6):747-51.

60. Rosenberg SA, Dudley ME. Cancer regression in patients with metastatic melanoma after the transfer of autologous antitumor lymphocytes. Proc Natl Acad Sci U.S.A. 2004;101 Suppl 2:14639-45.

61. Morgan RA, Dudley ME, Wunderlich JR et al. Cancer regression in patients after transfer of genetically engineered lymphocytes. Science 2006;314(5796):126-9.

62. Restifo NP, Dudley ME, Rosenberg SA. Adoptive immunotherapy for cancer: harnessing the $\mathrm{T}$ cell response. Nat Rev Immunol 2012;12(4):269-81.

63. Dudley ME, Yang JC, Sherry R et al. Adoptive cell therapy for patients with metastatic melanoma: evaluation of intensive myeloablative chemoradiation preparative regimens. J Clin Oncol 2008;26(32):5233-9.

64. Rosenberg SA, Dudley ME. Adoptive cell therapy for the treatment of patients with metastatic melanoma. Curr Opin Immunol 2009;21(2):233-40.

65. Rosenberg SA, Yang JC, Sherry RM et al. Durable complete responses in heavily pretreated patients with metastatic melanoma using T-cell transfer immunotherapy. Clin Cancer Res 2011;17(13):4550-7.

66. Bernatchez C, Radvanyi LG, Hwu P. Advances in the treatment of metastatic melanoma: adoptive T-cell therapy. Semin Onco 2012;39(2):215-26.

67. Velho TR, Kapiteijn E, Jager MJ. New therapeutic agents in uveal melanoma. Anticancer Res 2012;32(7):2591-8.

68. Seeger JM, Schmidt P, Brinkmann K et al. The Proteasome Inhibitor Bortezomib Sensitizes Melanoma Cells toward Adoptive CTL Attack. Cancer Res 2010;70(5):1825-34.

69. Tarhini AA, Iqbal F. CTLA-4 blockade: therapeutic potential in cancer treatments. Onco Targets Ther 2010;3:15-25.
70. Robert C, Ghiringhelli F. What is the role of cytotoxic T lymphocyte-associated antigen 4 blockade in patients with metastatic melanoma?. Oncologist 2009;14(8):848-61.

71. Hodi FS, O'Day SJ, McDermott DF et al. Improved survival with ipilimumab in patients with metastatic melanoma. N Engl J Med 2010;363(8):711-23.

72. Margolin K, Ernstoff MS, Hamid O et al. Ipilimumab in patients with melanoma and brain metastases: an open-label, phase 2 trial. Lancet Oncol 2012;13(5): 459-65.

73. Robert C, Thomas L, Bondarenko I et al. Ipilimumab plus dacarbazine for previously untreated metastatic melanoma. N Engl J Med 2011;364(26):2517-26.

74. Weber JS, Kähler KC, Hauschild A. Management of immune-related adverse events and kinetics of response with ipilimumab. J Clin Oncol 2012;30(21):2691-7.

75. Ribas A, Camacho LH, Lopez-Berestein G et al. Antitumor activity in melanoma and anti-self responses in a phase I trial with the anti-cytotoxic $\mathrm{T}$ lymphocyteassociated antigen 4 monoclonal antibody CP-675, 206. J Clin Oncol 2005;23(35):8968-77.

76. Camacho LH, Antonia S, Sosman J et al. Phase I/II trial of tremelimumab in patients with metastatic melanoma. J Clin Oncol 2009;27(7):1075-81.

77. Ribas A, Hauschild A, Kefford R et al. Phase III, open-label, randomized, comparative study of tremelimumab (CP-675,206) and chemotherapy (temozolomide [TMZ] or dacarbazine [DTIC]) in patients with advanced melanoma. J Clin Oncol 2008;26(May 20 suppl):abstr LBA0911.

78. Tarhini AA, Cherian J, Moschos SJ et al. Safety and efficacy of combination immunotherapy with interfero alfa- $2 \mathrm{~b}$ and tremelimumab in patients with stage IV melanoma. J Clin Oncol 2012;30(3):322-8.

79. Keir ME, Butte MJ, Freeman GJ, Sharpe AH. PD-1 and its ligands in tolerance and immunity. Annu Rev Immunol 2008;26:677-704.

80. Riley JL. PD-1 signaling in primary $\mathrm{T}$ cells. Immunol Rev 2009;229(1):114-25.

81. Brahmer JR, Drake CG, Wollner I et al. Phase I study of singleagent anti-programmed death-1 (MDX-1106) in refractory solid tumors: safety, clinical activity, pharmacodynamics, and immunologic correlates. J Clin Oncol 2010;28(19):3167-75.

82. Topalian SL, Hodi FS, Brahmer JR et al. Safety, activity, and immune correlates of andit-PD-1 antibody in cancer. N Engl J Med 2012;366(26):2443-54.

83. Narazaki H, Zhu Y, Luo L, Zhu G, Chen L. CD137 agonist antibody prevents cancer recurrence: contribution of CD137 on both hematopoietic and nonhematopoietic cells. Blood 2010;115(10):1941-8.

84. Yang $Y$, Yang $S$, Ye $Z$ et al. Tumor cells expressing antiCD137 scFv induce a tumor-destructive environment. Cancer Res 2007;67(5):2339-44.

85. Pennisi M. A mathematical model of immune-systemmelanoma competition. Comput Math Methods Med 2012:850754. 
86. Melero I, Hervas-Stubbs S, Glennie M, Pardoll DM, Chen L. Immunostimulatoru monoclonal antibodies for cancer therapy. Nat Rev Cancer 2007;7(2):95-106.

87. Sznol M, Hodi FS, Margolin K et al. Phase I study of BMS-663513, a fully human anti-CD137 agonist monoclonal antibody, in patients (pts) with advanced cancer (CA). J Clin Oncol 2008;26(May 20 suppl:abstr 3007.

88. Davies H, Bignell GR, Cox C et al. Mutations of the BRAF gene in human cancer. Nature 2002;417:949-54.

89. Pollock PM, Meltzer PS. A genome-based strategy uncovers frequent BRAF mutations in melanoma. Cancer Cell 2002;2:5-7.

90. Brose MS, Volpe P, Feldman M et al. BRAF and RAS mutations in human lung cancer and melanoma. Cancer Res 2002;62:6997-7000.

91. Pollock PM, Harper UL, Hansen KS et al. High frequency of BRAF mutations in nevi. Nat Genet 2003;33:19-20.

92. Wilhelm SM, Carter C, Tang L et al. BAY 43-9006 exhibits broad spectrum oral antitumor activity and targets the RAF/MEK/ERK pathway and receptor tyrosine kinases involved in tumor progression and angiogenesis. Cancer Res 2004;64:7099-109.

93. Adnane L, Trail PA, Taylor I, Wilhelm SM. Sorafenib (BAY 43-9006, Nexavar), a dual-action inhibitor that targets RAF/MEK/ERK pathway in tumor cells and tyrosine kinases VEGFR/PDGFR in tumor vasculature. Methods Enzymol 2006;407:597-612.

94. Eisen T, Ahmad T, Flaherty KT et al. Sorafenib in advanced melanoma: A phase II randomised discontinuation trial analysis. Br J Cancer 2006;95:581-586.

95. Hauschild A, Agarwala SS, Trefzer U et al. Results of a phase III, randomized, placebo-controlled study of sorafenib in combination with carboplatin and paclitaxel as second-line treatment in patients with unresectable stage III or stage IV melanoma. J Clin Oncol 2009;27(17):2823-30.

96. McDermott DF, Sosman JA, Gonzalez R et al. Doubleblind randomized phase II study of the combination of sorafenib and dacarbazine in patients with advanced melanoma: a report from the 11715 Study Group. J Clin Oncol 2008;26(13):2178-85.

97. Amaravadi RK, Schuchter LM, Kramer A et al. Preliminary results of a randomized phase II study comparing two schedules of temozolomide in combination with sorafenib in patients with advanced melanoma. ASCO Annual Meeting Proceedings Part I. J Clin Oncol 2006;24:18S (June 20 Supplement).

98. Eggermont AM, Robert C. New drugs in melanoma: it's a whole new world. Eur J Cancer 2011;47(14):2150-7.

99. Chen J, Shen Q, Labow M, Gaither LA. Protein kinase D3 sensitizes RAF inhibitor RAF265 in melanoma cells by preventing reactivation of MAPK signaling. Cancer Res 2011;71(12):4280-91.

100. Sharfman WH, Hodi FS, Lawrence DP et al. Results from the first-in-human (FIH) phase I study of the oral
RAF inhibitor RAF265 administered daily to patients with advanced cutaneous melanoma. J Clin Oncol 2011;29 (suppl) abstr 8508.

101. Su Y, Vilgelm AE, Kelley MC et al. RAF265 inhibits the growth of advanced human melanoma tumors. Clin Cancer Res 2012;18(8):2184-98.

102. Joseph EW, Pratilas CA, Poulikakos PI et al. The RAF inhibitor PLX4032 inhibits ERK signaling and tumor cell proliferation in a V600E BRAF-selective manner. Proc Natl Acad Sci USA 2010;107:14903-8.

103. Flaherty KT, Puzanov I, Kim KB et al. Inhibition of mutated, activated BRAF in metastatic melanoma. N Engl J Med 2010;363(9):809-19.

104. Ribas A, Kim KB, Schuchter LM et al. BRIM-2: An open-label, multicenter phase II study of vemurafenib in previously treated patients with BRAF V600E mutation-positive metastatic melanoma. J Clin Oncol 2011;29 (suppl) abstr 8509.

105. Chapman PB, Hauschild A, Robert C et al. Improved survival with vemurafenib in melanoma with BRAF V600E mutation. N Engl J Med 2011;364(26):2507-16.

106. Sosman JA, Kim KB, Schuchter L et al. Survival in BRAF V600-mutant advanced melanoma treated with vemurafenib. N Engl J Med 2012;366(8):707-14.

107. Soffietti R, Trevisan E, Rudà R. Targeted therapy in brain metastasis. Curr Opin Oncol 2012 [Epub ahead of print].

108. Dummer R, Rinderknecht J, Goldinger SM et al. An open-label pilot study of vemurafenib in previously treated metastatic melanoma patients with brain metastases. J Clin Oncol 2011;29 (suppl) abstr 8548.

109. Young K, Minchom A, Larkin J. BRIM-1, -2 and -3 trials: improved survival with vemurafenib in metastatic melanoma patients with a BRAF(V600E) mutation. Future Oncol 2012;8(5):499-507.

110. Ravnan MC, Matalka MS. Vemurafenib in Patients With BRAF V600E Mutation-Positive Advanced Melanoma. Clin Ther 2012;34(7):1474-86.

111. Nazarian R, Shi H, Wang Q et al. Melanomas acquire resistance to B-RAF(V600E) inhibition by RTK or N-RAS upregulation. Nature 2010;468(7326):973-7.

112. Kudchadkar R, Paraiso KH, Smalley KS. Targeting mutant BRAF in melanoma: current status and future development of combination therapy strategies. Cancer J 2012;18(2):124-31.

113. Kefford R, Arkenau H, Brown MP et al. Phase I/II study of GSK2118436, a selective inhibitor of oncogenic mutant BRAF kinase, in patients with metastatic melanoma and other solid tumors. J Clin Oncol 2010;28:15s (suppl) abstr 8503.

114. Hauschild A, Grob JJ, Demidov LV et al. Dabrafenib in BRAF-mutated metastatic melanoma: a multicentre, open-label, phase 3 randomised controlled trial. Lancet 2012;380(9839):358-65.

115. Long GV, Kefford RF, Carr P et al. Phase 1/2 Study of GSK2118436, a Selective Inhibitor of V600 Mutant 
(Mut) BRAF Kinase: Evidence of Activity in Melanoma Brain Metastases (Mets), ESMO 2010: Abst 5016.

116. Falchook GS, Long GV, Kurzrock R et al. Dabrafenib in patients with melanoma, untreated brain metastases, and other solid tumours: a phase 1 dose-escalation trial. Lancet 2012;379(9829):1893-901.

117. Greger JG, Eastman SD, Zhang V et al. Combinations of BRAF, MEK, and PI3K/mTOR inhibitors overcome acquired resistance to the BRAF inhibitor GSK2118436 dabrafenib, mediated by NRAS or MEK mutations. Mol Cancer Ther 2012;11(4):909-20.

118. Anforth RM, Blumetti TC, Kefford RF et al. Cutaneous Manifestations of Dabrafenib (GSK2118436): A Selective Inhibitor of Mutant BRAF in patients with Metastatic Melanoma. Br J Dermatol 2012 [Epub ahead of print].

119. Falchook GS, Lewis KD, Infante JR et al. Activity of the oral MEK inhibitor trametinib in patients with advanced melanoma: a phase 1 dose-escalation trial. Lancet Oncol 2012;13(8):782-9.

120. Kirkwood JM, Bastholt L, Robert C et al. Phase II, open-label, randomized trial of the MEK1/2 inhibitor selumetinib as monotherapy versus temozolomide in patients with advanced melanoma. Clin Cancer Res 2012;18(2):555-67.

121. Holt SV, Logié A, Odedra R et al. The MEK1/2 inhibitor, selumetinib (AZD6244; ARRY-142886), enhances anti-tumour efficacy when combined with conventional chemotherapeutic agents in human tumour xenograft models. Br J Cancer 2012;106(5):858-66.

122. Ferguson J, Arozarena I, Ehrhardt M, Wellbrock C. Combination of MEK and SRC inhibition suppresses melanoma cell growth and invasion. Oncogene 2012 [Epub ahead of print].

123. Falchook GS, Lewis KD, Infante JR et al. Activity of the oral MEK inhibitor trametinib in patients with advanced melanoma: a phase 1 dose-escalation trial. Lancet Oncol 2012;13(8):782-9.

124. Flaherty KT, Robert C, Hersey P et al. Improved survival with MEK inhibition in BRAF-mutated melanoma. N Engl J Med 2012;367(2):107-14.

125. von Euw E, Atefi M, Attar N et al. Antitumor effects of the investigational selective MEK inhibitor TAK733 against cutaneous and uveal melanoma cell lines. Mol Cancer 2012;11(1):22.

126. Vihinen PP, Hernberg M, Vuoristo MS et al. A phase II trial of bevacizumab with dacarbazine and daily low-dose interferon-alpha2a as first line treatment in metastatic melanoma. Melanoma Res 2010;20(4):318-25.

127. Grignol VP, Olencki T, Relekar K et al. A phase 2 trial of bevacizumab and high-dose interferon alpha $2 \mathrm{~B}$ in metastatic melanoma. J Immunother 2010;34(6):509-15.

128. Kim KB, Sosman JA, Fruehauf JP et al. BEAM: a randomized phase II study evaluating the activity of bevacizumab in combination with carboplatin plus paclitaxel in patients with previously untreated advanced melanoma. J Clin Oncol 2012;30(1):34-41.
129. von Moos R, Seifert B, Simcock M et al. First-line temozolomide combined with bevacizumab in metastatic melanoma: a multicentre phase II trial (SAKK 50/07). Ann Oncol 2012;23(2):531-6.

130. Kruijff $S$, Bastiaannet E, Brouwers $A H$ et al. Use of S-100B to evaluate therapy effects during bevacizumab induction treatment in AJCC stage III melanoma. Ann Surg Oncol 2012;19(2):620-6.

131. Kelly RJ, Rixe O. Axitinib (AG-013736). Recent Results Cancer Res 2010;184:33-44.

132. Choueiri TK. Axitinib, a novel anti-angiogenic drug with promising activity in various solid tumors. Curr Opin Investig Drugs 2008;9(6):658-71.

133. Fruehauf J, Lutzky J, McDermott $D$ et al. Multicenter, phase II study of axitinib, a selective second-generation inhibitor of vascular endothelial growth factor receptors 1,2 , and 3 , in patients with metastatic melanoma. Clin Cancer Res 2011;17(23): 7462-9.

134. Bose A, Lowe DB, Rao A, Storkus WJ. Combined vaccine+axitinib therapy yields superior antitumor efficacy in a murine melanoma model. Melanoma Res 2012;22(3):236-43.

135. Glen H, Mason S, Patel H, Macleod K, Brunton VG. E7080, a multi-targeted tyrosine kinase inhibitor suppresses tumor cell migration and invasion. BMC Cancer 2011;22;11:309.

136. Boss DS, Glen H, Beijnen JH et al. A phase I study of E7080, a multitargeted tyrosine kinase inhibitor, in patients with advanced solid tumours. Br J Cancer 2012;8;106(10):1598-604.

137. Moschos SJ, Sander CA, Wang Wetal. Pharmacodynamic (phase 0) study using etaracizumab in advanced melanoma. J Immunother 2010;33(3):316-25.

138. Hersey P, Sosman J, O'Day $S$ et al. A randomized phase 2 study of etaracizumab, a monoclonal antibody against integrin alpha(v)beta(3), + or - dacarbazine in patients with stage IV metastatic melanoma. Cancer 2010;116(6):1526-34.

139. Jansen B, Wacheck V, Heere-Ress E et al. Chemosensitisation of malignant melanoma by BCL2 antisense therapy. Lancet 2000;356(9243):1728-33.

140. Bedikian AY, Millward M, Pehamberger $\mathrm{H}$ et al. Oblimersen Melanoma Study Group: Bcl-2 antisense (oblimersen sodium) plus dacarbazine in patients with advanced melanoma: the Oblimersen Melanoma Study Group. J Clin Oncol 2006;24(29):4738-45.

141. Spugnini EP, Biroccio A, De Mori R et al. Electroporation increases antitumoral efficacy of the bcl-2 antisense G3139 and chemotherapy in a human melanoma xenograft. J Transl Med 2011;28;9:125.

142. Madonna G, Ullman CD, Gentilcore G, Palmieri G, Ascierto PA. NF- $\mathrm{KB}$ as potential target in the treatment of melanoma. J Transl Med 2012;10:53.

143 Amiri KI, Horton LW, LaFleur BJ, Sosman JA and Richmond A. Augmenting chemosensitivity of malignant melanoma tumors via proteasome inhibition: 
implication for bortezomib (VELCADE, PS-341) as a therapeutic agent for malignant melanoma. Cancer Res 2004;64(14):4912-8.

144. Su Y, Amiri KI, Horton LW et al. A Phase I Trial of Bortezomib with Temozolomide in Patients with Advanced Melanoma: Toxicities, Antitumor Effects, and Modulation of Therapeutic Targets. Clin Cancer Res 2010;16(1):348-57.

145. Croghan GA, Suman VJ, Maples WJ et al. A study of paclitaxel, carboplatin, and bortezomib in the treatment of metastatic malignant melanoma: a phase 2 consortium study. Cancer 2010;116(14):3463-8.

146. Yeramian A, Sorolla A, Velasco A et al. Inhibition of activated receptor tyrosine kinases by Sunitinib induces growth arrest and sensitizes melanoma cells to Bortezomib by blocking Akt pathway. Int J Cancer 2012;130(4):967-78.

147. Robertson GP. Functional and therapeutic significance of Akt deregulation in malignant melanoma. Cancer Metastasis Rev 2005;24(2):273-85.

148. Sánchez-Hernández I, Baquero P, Calleros L, Chiloeches A. Dual inhibition of (V600E)BRAF and the PI3K/ $\mathrm{AKT} / \mathrm{mTOR}$ pathway cooperates to induce apoptosis in melanoma cells through a MEK-independent mechanism. Cancer Lett 2012;314(2):244-55.

149. Pópulo H, Soares P, Lopes JM. Insights into melanoma: targeting the mTOR pathway for therapeutics. Expert Opin Ther Targets 2012;16(7):689-705.

150. Rao RD, Windschitl HE, Allred JB et al. Phase II trial of the mTOR inhibitor everolimus (RAD-001) in metastatic melanoma. ASCO Annual Meeting Proceedings Part I. J Clin Oncol 2006;24:18S (June 20 Supplement).

151. Hainsworth JD, Infante JR, Spigel DR et al. Bevacizumab and everolimus in the treatment of patients with metastatic melanoma: a phase 2 trial of the Sarah Cannon Oncology Research Consortium. Cancer 2010;116(17):4122-9.

152. O'Reilly T, Lane HA, Wood JM et al. Everolimus and PTK/ZK show synergistic growth inhibition in the orthotopic BL16/BL6 murine melanoma model. Cancer Chemother Pharmacol 2011;67(1):193-200.

153. Fury MG, Sherman E, Haque $S$ et al. A phase I study of daily everolimus plus low-dose weekly cisplatin for patients with advanced solid tumors. Cancer Chemother Pharmacol 2012;69(3):591-8.

154. Margolin K, Longmate J, Baratta T et al. CCI-779 in metastatic melanoma: a phase II trial of the California Cancer Consortium. Cancer 2005;104(5):1045-8.
155. Davies MA, Fox PS, Papadopoulos NE et al. Phase I study of the combination of sorafenib and temsirolimus in patients with metastatic melanoma. Clin Cancer Res 2012;15;18(4):1120-8.

156. Margolin KA, Moon J, Flaherty LE et al. Randomized phase II trial of sorafenib with temsirolimus or tipifarnib in untreated metastatic melanoma (S0438). Clin Cancer Res 2012;18(4):1129-37.

157. Tabone-Eglinger S, Wehrle-Haller M, Aebischer N, Jacquier MC, Wehrle-Haller B. Membrane-bound Kit ligand regulates melanocyte adhesion and survival, providing physical interaction with an intraepithelial niche. FASEB J 2012 [Epub ahead of print].

158. Yoshida H, Kunisada T, Grimm T, Nishimura EK, Nishioka E, Nishikawa SI. Review: melanocyte migration and survival controlled by SCF/c-kit expression. J Investig Dermatol Symp Proc 2001;6(1):1-5.

159. Willmore-Payne C, Holden JA, Hirschowitz S, Layfield LJ. BRAF and c-kit gene copy number in mutation-positive malignant melanoma. Hum Pathol 2006;37(5):520-7.

160. Curtin JA, Busam K, Pinkel D, Bastian BC. Somatic activation of KIT in distinct subtypes of melanoma. J Clin Oncol 2006;24(26):4340-6.

161. Carvajal RD, Antonescu CR, Wolchok JD et al. KIT as a therapeutic target in metastatic melanoma. JAMA 2011;305(22):2327-34.

162. Guo J, Si L, Kong Y et al. Phase II, open-label, singlearm trial of imatinib mesylate in patients with metastatic melanoma harboring c-Kit mutation or amplification. J Clin Oncol 2011;29(21):2904-9.

163. Minor DR, Kashani-Sabet M, Garrido M, O’Day SJ, Hamid O, Bastian BC. Sunitinib therapy for melanoma patients with KIT mutations. Clin Cancer Res 2012;18(5):1457-63.

164. Centers for Disease Control and Prevention Department of Health and Human Services: National Program of Cancer Registries (NPCR). Available from: http://apps.nccd.cdc.gov/uscs/toptencancers.aspx [Last accessed: 15 August 2012].

165. Seigler HF, Lucas VS Jr, Pickett NJ, Huang AT. DTIC, CCNU, bleomycin and vincristine (BOLD) in metastatic melanoma. Cancer 1980;46(11):2346-8. 